\title{
A filmagem acidental dos acontecimentos e o regime visual do século XXI
}

\section{Felipe da Silva Polydoro}

Professor adjunto da Faculdade de Comunicação da Universidade de Brasília (FAC-UnB).

E-mail: felipepolydoro@gmail.com
Resumo: Este artigo discute, no regime contemporâneo das imagens, a prevalência do ímpeto documental, do apelo realista e de uma estética da urgência associada à ubiquidade das câmeras. Para tanto, toma como objeto de análise alguns registros em vídeo dos atentados contra o World Trade Center, em setembro de 2001. Entende-se aqui que o acontecimento em questão representa um marco neste novo regime visual. O primeiro, no século XXI, a contar com uma elevada quantidade de vídeos e fotografias de amadores. Priorizaremos a observação dos três registros que documentam, acidentalmente, o choque do primeiro avião e remetem mais diretamente a um regime visual no qual convivem os fenômenos, a princípio antagônicos, de espetacularização e vigilância.

Palavras-chave: Regime Visual; Imagens Amadoras; Análise da Imagem.

\section{Accidental footage of events and the visual regime of 21st century}

Abstract: In this paper, we discuss, in the contemporary regime of images, the prevalence of documentary impetus, the realistic appeal and an aesthetic of the urgency associated with the ubiquity of the cameras. It takes as object of analysis video recordings of the attacks against the World Trade Center in September 2001. We understand that the event represents a milestone in this new visual regime. It is the first in the 21st century to count on a high number of amateur videos and photographs. We will observe mainly the three footage that accidentally documented the shock of the first plane and refer more directly to a visual regime in which coexist the phenomena of spectacularization and vigilance.

Keywords: Visual regime; Amateur Images; Analysis of Image. 


\section{Introdução: o mundo tomado por câmeras}

Em texto publicado em 1946, o crítico André Bazin já chamava a atenção com um tom irônico, diga-se - para o apelo de imagens em movimento que surpreendem um acontecimento marcante em sua própria ocorrência. "Nada se compara ao acontecimento único, filmado ao vivo, no próprio instante de sua criação" (BAZIN, 2014: 42). O tema da reflexão eram os filmes da guerra recém encerrada, cuja atratividade junto ao público "só receiam a concorrência dos terremotos, das erupções vulcânicas, das enchentes e do fim do mundo" (BAZIN, 2014: 42). O apreço pelos flagrantes factuais, sobretudo envolvendo guerra, violência e tragédia, seria expressão da "vontade de presença do homem moderno", que explica a fixação nas atualidades e a necessidade de "assistir à própria História" e esclarece até mesmo o sucesso do cinema.

Como a História não é um balé totalmente programado de antemão, convém dispor, ao longo de sua passagem, do máximo de câmeras possível para se certificar de que ela será filmada no momento em que acontece. (BAZIN, 2014: 42)

Bazin (2014: 43) admirava-se, no final dos anos 1940, em ver o mundo tomado por câmeras e imagens, "quando inúmeras objetivas de Bell-Howell espiam, em todas as esquinas, acontecimentos, sinais pitorescos, curiosos ou terríveis de nosso destino". Assombrava-se ainda com a enorme disponibilidade de documentos audiovisuais da guerra, reportagens de atualidades que serviam de matéria-prima para inúmeros filmes lançados naqueles anos - caso da série de documentários estadunidenses Why we fight (de Frank Capra, entre 1942-1945), objeto do crítico francês no texto citado.

Como sabemos, este ímpeto documental atravessaria décadas e ganharia intensidade até a chegada do século 21, quando anônimos dotados de equipamentos que filmam e fotografam encontram não apenas modos de registrar obsessivamente o cotidiano, mas também fazem esses decalques dos fatos circularem de imediato nos ambientes digitais. Os acontecimentos de 11 de setembro nos Estados Unidos são emblemáticos dessa nova ordem comunicacionalmidiática. Além de as ocorrências terem sido acompanhadas quase integralmente ao vivo por milhões de telespectadores (a televisão mostrou ao vivo o choque do segundo avião e a queda das duas torres), o legado é uma coleção interminável de imagens fixas e em movimento ao alcance de qualquer internauta no YouTube ou em sites criados especialmente com o fim de armazenar documentos sobre

${ }^{2}$ Há pelo menos dois importantes sites que armazenam centenas de vídeos e fotografias dos atentados de 11 de setembro. Um deles, na verdade, é uma seção enorme dentro do portal norte-americano Internet Arquive, dedicada apenas a imagens do acontecimento: http://bit.ly/2Qu34nT. Acesso em: 13 nov. 2018. O outro site é uma iniciativa do National September 11 Memorial \& Museum, museu situado no local onde ficavam as duas torres: um espaço na web batizado de Make History, que estimula as pessoas a postarem fotos, vídeos e histórias escritas sobre experiências individuais na ocorrência do atentado: http://bit.ly/2Mdxv3q. Acesso em: 13 nov. 2018. este evento histórico ${ }^{2}$. A coleção de objetos audiovisuais disponíveis na web e, de alguma forma, ligados ao acontecimento inclui desde fragmentos da cobertura televisiva ao vivo até imagens que as emissoras evitaram veicular ou veicularam com discrição, sobretudo os vídeos que mostram as vítimas pulando do alto das torres em chamas.

Trata-se do primeiro acontecimento dessa magnitude a cultivar uma quantidade tão grande de flagrantes amadores, tornando-se uma espécie de marco de um novo regime visual. É notável que haja três filmagens do impacto do primeiro avião contra a torre norte do World Trade Center (WTC), fato imprevisto e cuja captação seria, à primeira vista, fruto de coincidência. Nos três, o choque surpreende câmeras em operação. Neste artigo, analisaremos alguns registros audiovisuais dos atentados contra o WTC, tendo como questão norteadora a compreensão de um regime atual das imagens marcado pelo ímpeto documental (incluído o apelo dessa documentação junto ao espectador contemporâneo). Priorizaremos a observação dos três registros que documentam o primeiro choque e remetem mais diretamente a um regime visual no qual convivem os fenômenos a princípio antagônicos de espetacularização e vigilância. 


\section{Um olhar sem sujeito}

${ }^{3}$ Nos anos 1960, Warhol teve a ideia de um programa de televisão chamado "Nothing Special" ("Nada de especial"), também vazio de acontecimentos. Conforme Menick (2004, s.p), em 1969, Warhol descreveu essa ideia da seguinte forma: “Nós sentaríamos lá e esperaríamos que algo acontecesse mas nada aconteceria”. ("We'd just sit there nothing would").

4 "Unlike contemporary surveillance images, Warhol's Empire seems to occupy a kind of dream world, shrouded in its $16 \mathrm{~mm}$ haziness". and wait for something to happen and

O incidente envolvendo uma obra do artista alemão Wolfgang Staehle e os atentados ao WTC é revelador da tensão entre vigilância e espetáculo no regime visual contemporâneo. $O$ trabalho de Staehle investiga a relação entre tecnologia, visão e temporalidade numa época em que as mediações vivem sob o regime do tempo real. Em Empire 24/7, de 1996, o artista identificado com a arte em novas mídias fixou uma webcam em direção ao Empire State Building, em Nova York, e a manteve em operação indefinidamente, num presente contínuo. As imagens ininterruptas eram projetadas, com um atraso irrisório, numa parede na galeria do centro de arte e mídia ZKM, na cidade de Karlsruhe, Alemanha. A webcam disparava uma nova fotografia a cada quatro segundos, modificando o quadro - não um vídeo, mas uma lenta sucessão de fotografias.

A obra homenageia e dialoga com o filme Empire, de Andy Warhol, um plano fixo de oito horas e cinco minutos do prédio nova-iorquino, em preto-e-branco, silencioso, feito em 1963, que compõe o conjunto de trabalhos audiovisuais warholianos centrados numa temporalidade alongada e monótona, vazia de acontecimentos, de visionamento quase insuportável ${ }^{3}$. Um ritmo em contraste com a pontuação cada vez mais acelerada do tempo nos meios de comunicação, com a rápida expansão da televisão, na qual o paradigma do ao vivo convive com a repetição. O filme de Warholque, além de tudo, era projetado numa velocidade um terço mais lenta - também se contrapunha a suas célebres pinturas do movimento arte pop, nas quais a repetição de uma imagem idêntica alude a uma temporalidade acelerada e em fragmentos.

Concebida mais de trinta anos depois, a obra Empire 24/7 expressa transformações tanto no regime visual quanto no regime temporal. O filme de Warhol já prenunciava o funcionamento perpétuo das câmeras de vigilância, mas ainda admitia um olhar humano. "Diferentemente das imagens de vigilância contemporâneas, o Empire de Warhol parece ocupar algo como um mundo de sonho, envolto na névoa de seus 16 milímetros" (RODNEY, 2005: 42 , tradução nossa) $)^{4}$. Votado a uma resistência contemplativa, o filme também sugere que, ao fundo da aceleração das imagens própria ao paradigma do ao vivo, há uma inércia fundamental.

A webcam 24/7 de Staehle, operando sem interrupção meses a fio, uma transmissão cuja duração afasta-se das possibilidades físicas humanas, assume sua condição de olhar maquínico. A perenidade da imagem manifesta uma autoconsciência de seu estatuto de vigilância.

No trabalho de Staehle, há um entendimento de que o vídeo pode continuar sozinho sem ser visto; é um exercício mecânico e digitalizado, em um registro sem fim. Como em qualquer vigilância digital, a imagem pode ser exibida e revista quando necessário, mas é desnecessário assisti-la do início ao fim. (MENICK, 2004, s.p., tradução nossa) ${ }^{5}$

5 "In Staehle's work, there is an understanding that the video can continue on its own without being watched; it is a mechanical, digitized exercise in endless recording. As with any digital surveillance, the image can be screened and reviewed when necessary, but it is unnecessary to watch it all from beginning to end."
Aobra 2001 ampliava o projeto de Empire 24/7. Agora sãotrês webcamsfuncionando em tempo real, atualizadas igualmente a cada quatro segundos, apontadas para três paisagens em diferentes partes do mundo: uma torre de televisão em Berlim, um monastério na Baviera e um plano aberto do sul de Manhattan. Neste último caso, o artista usou duas câmeras de internet posicionadas no décimo andar de um edifício do bairro do Brooklin, que fundiam a imagem numa visão panorâmica. Desta vez, as imagens não foram disponibilizadas online. Funcionavam no modo do circuito interno: encontravam-se projetadas, em tempo real e em tamanho ampliado, numa parede da galeria Postmasters, em Nova York. Além da lentidão dessas filmagens intermináveis carentes de acontecimentos significativos - cujo tempo contínuo e vazio de pontuações define-se como contraponto e, ao mesmo tempo, estatuto último do tempo real da conectividade - o trabalho tematizava 
6 "He was presenting the omniscience of the surveillance camera as society's boon and burden." ainda o caráter construído da simultaneidade. Conforme Friend (2011, s.p, tradução nossa), Staehle visava "apresentar a onisciência da câmera de vigilância como a benção e o fardo da sociedade [moderna]"6. Quanto à ideia de progresso e de precisão associadas à construção do tempo na modernidade, a perspectiva era crítica, revelada pela epígrafe exibida na entrada da galeria, de autoria do filósofo alemão Martin Heidegger, cujo pensamento associava o avanço do mundo da técnica à decadência do humanismo.

Quando o mais afastado canto do globo tiver sido conquistado tecnicamente e explorado economicamente...; quando você puder "experienciar" simultaneamente um atentado contra o Rei da França e um concerto sinfônico em Tóquio; quando o tempo é apenas rapidez, instantaneidade e simultaneidade..; ainda paira sobre todo esse tumulto, como um espectro, a pergunta: para quê? - para onde? e o que agora? (apud FRIEND, 2011, s.p, tradução nossa) ${ }^{7}$

7 "When the farthest corner of the globe has been conquered technologically and can be exploited economically; when you can simultaneously 'experience' an assassination attempt against a king in France and a symphony concert in Tokyo; when time is nothing but speed, instantaneity, and simultaneity...; there still looms like a specter over all this uproar the question: what for? - where to? - and what then?"

${ }^{8}$ Há um fragmento curto do momento em que a câmera de Staehle registra o choque do primeiro avião com a torre do WTC neste vídeo disponível no YouTube: http://bit.ly/2WrxtZv. Acesso em: 23 maio 2017.

${ }^{9}$ Conforme Friend (2011), Staehle evitou engajar-se em um debate de natureza artística sobre a obra em meio à tragédia com quase três mil mortos. Também optou por não disponibilizar as imagens às emissoras de televisão - de lá para cá, foram apresentadas apenas em catálogos e em algumas retrospectivas do artista.
A exposição foi inaugurada em 6 de setembro de 2001 e o dispositivo de Staehle documentou todo o atentado às torres do World Trade Center, situadas na porção central do panorama do sul de Manhattan ${ }^{8}$. Captou inclusive o choque do primeiro avião, constituindo-se em um dos três registros visuais do impacto inaugural. Vê-se primeiro o avião se aproximando, no canto superior direito, quase fora da imagem - um pequeno ponto, imperceptível numa observação ligeira. No frame seguinte, quatro segundos depois, há três bolas de fumaça saindo pelos três lados visíveis da torre. A amplitude da fumaça ainda é restrita, indicando que a imagem captura o instante do impacto e o início da explosão. Mais quatro segundos e vemos uma fumaça já espessa, acompanhada de fogo, que ganha altura. Trata-se de um registro silencioso, em um plano panorâmico e fixo com o ponto de vista situado a quilômetros de distância das torres: uma representação indiferente e impessoal também típica das filmagens de vigilância. Depois de testemunhar o acontecimento traumático, o dispositivo de Staehle vai continuar fotografando, inabalado e a cada quatro segundos, o horizonte já sem as torres: um olhar definitivamente sem sujeito, inviolado pela experiência.

Desnecessário dizer que o projeto original do artista não previa que seu dispositivo flagrasse um acontecimento com a dimensão do atentado terrorista de 11 de setembro. Ao projetar na parede de uma galeria de arte, em tamanho avantajado, uma imagem em tempo real de uma webcam, Staehle pretendia, por meio do gesto de deslocamento, problematizar esse olhar insistente do regime de visibilidade da vigilância, que conta entre suas marcas a gravação interminável de imagens vazias, desprovidas de fatos significativos. Havia também um impulso duchampiano: o deslocamento, para um ambiente artístico, de um objeto-imagem cada vez mais central no cotidiano. A realidade vista - ou mediada - pelas telas de computadores (o plano panorâmico de Manhattan remete ao cartão postal e às paisagens da pintura, mas também às imagens de fundo de tela dos notebooks). Além disso, a projeção na galeria de arte à parte, trata-se de uma filmagem de baixa complexidade ao alcance de internautas familiarizados com o uso de webcams. Ainda, a intenção deliberada de Staehle era expressar uma espectatorialidade mediada pela câmera mas livre do filtro institucional dos grupos tradicionais de comunicação de massa - uma alusão à ideia, tão cara ao valor estético das imagens amadoras, de uma representação cujo caráter imediato e "imediado" sustenta-se no desvio do controle das grandes corporações de mídia.

O flagrante de Staehle foi acidental, inadvertidamente captado pelo dispositivo em um processo em andamento. Conforme Menick (2004), críticos de arte divergiram sobre o significado do acidente na lógica interna da obra, que complexificava os regimes visual e temporal contemporâneos apostando em tempos lentos e na ausência de acontecimentos significativos - como o artista já havia feito em Empire 24/7 e Andy Warhol no Empire original ${ }^{9}$. 
10 "When it came time for reviewers to determine the exact effect the attacks had on Staehle's work, they diverged, digressed, grasped for meaning. Although all reviews of '2001' evidenced some shade of praise, the responses were mixed equally with ambivalence and indecision. Something had obviously happened, but for reviewers that's about as clear as things got."
Quando chegou a hora de os críticos determinarem o exato efeito dos ataques no trabalho de Staehle, eles divergiram, digressionaram, procuraram por sentido. Embora todas as críticas de "2001" tenham sido de algum modo elogiosas, as respostas expressavam ambivalência e indecisão. Alguma coisa obviamente aconteceu, mas para os críticos isso é o máximo que pôde ser dito com clareza. (MENICK, 2004, s.p, tradução nossa) ${ }^{10}$

Esse episódio dá relevo a uma duplicidade não conflitiva, e sim complementar, deste regime visual do espalhamento de todos os tipos de câmeras, no qual o conceito de vigilância constitui um vetor inescapável (assim como a noção de espetáculo). De um lado, o vazio que expressa o ideal ontológico dos vídeos de vigilância de circuito fechado, imagem que:

\begin{abstract}
Mergulha em si mesma como se mergulha no nada. [...] Nos circuitos fechados em que o tempo é contínuo e a duração infinita (salvo em caso de pane das máquinas), a imagem adere temporalmente ao real até se identificar integralmente a ele em sua quase eternidade visual, isto é, em sua vacuidade mesma, no vazio que ele encarna soberanamente. [...] Eis aí o vídeo do vazio: nada a filmar, ninguém para filmar, a filmagem fazendo-se sozinha e sem traço. (DUBOIS, 2004: 52)
\end{abstract}

De outro lado, as filmagens perpétuas e distribuídas como uma abertura à intervenção do acaso, do imprevisto e do não-programado. Neste caso, a irrupção do real mobilizará mais a atenção quando inserida em imagens no contexto de acontecimentos espetaculares e que obedeçam, do ponto de vista formal, a uma estética do choque.

Foucault (1987) descreveu como as instituições disciplinares da modernidade (hospitais, escolas, prisões) organizaram formas de observação permanente dos sujeitos em um modelo panóptico (situação de visibilidade total indissociável dos processos de subjetivação). No contemporâneo, essa vigilância foi gradativamente distribuída: o olhar outrora centralizado no poder dispersou-se pelos sujeitos, o Big Brother converteu-se em uma coleção de "little brothers" (LYON, 2010) armados com câmeras. Essa passagem está diagnosticada por Deleuze (1992: 225) em termos da substituição das sociedades disciplinares pela sociedade de controle, na qual as estruturas rígidas e quadriculadas da disciplina dão lugar a estruturas flexíveis e moduláveis que formam um "sistema de geometria variável".

Conforme Bruno (2004), o empenho subjacente ao paradigma do controle vai prioritariamente no sentido da dissuasão e não da produção de uma imagem impressionante. Busca-se demover alguém de efetuar determinada ação antes de sua ocorrência (em vez de punir uma infração já ocorrida). O movimento temporal aqui é o da antecipação e da premeditação. $O$ procedimento tem natureza profilática, portanto não é à toa que, tantas vezes, os acontecimentos surpreendem uma filmagem já em operação, pois o sentido delas é exatamente o de antecipar-se aos eventos (de preferência, evitando-os).

$\mathrm{Na}$ atualidade, trata-se sobretudo de ver adiante, de prever e predizer, a partir dos cruzamentos e análises de dados, indivíduos e seus atos potenciais, seja para contê-los (como no caso de crimes, doenças, onde tende a predominar uma vigilância preventiva), seja para incitá-los (como no caso do consumo, da publicidade e do marketing). (BRUNO, 2007, s.p)

Nesta perspectiva de uma etapa avançada da vigilância marcada pelo dispersão de câmeras, o apelo das imagens em si e a atenção que mobilizam servem, sobretudo, a uma função mais fundamental: a incitação à produção e consumo permanentes de registros do mundo. Partindo de um arcabouço conceitual 
tributário às noções de vigilância e controle, Bruno (2007) cunhou a expressão "estética do flagrante", que designa exatamente a captação acidental, sobretudo por câmeras de vigilância ou operadas por amadores, de algum fato relevante ou curioso.

Neste trecho, Bruno (2007, s.p) sintetiza a potência e a atratividade da estética do flagrante:

O apelo destas imagens na captura da atenção de outros espectadores espalhados diante de diferentes telas (de computador, de celular, de televisão) parece residir não somente no seu conteúdo, mas também naquilo que, na sua forma, indica as condições de sua produção, tornando-as ainda mais efetivas como imagens de vigilância. Os ruídos das imagens amadoras indicam uma casualidade, uma urgência, um ar não intencional, improvisado e não retocado que amplia o seu efeito de real e de vigilância. Além disso, a excitação do flagrante presente na imagem supõe um observador oculto, colocando o espectador na condição de voyeur.

O complemento da vigilância stricto sensu é o conjunto de filmagens operadas pelas pessoas comuns tornadas objeto e, cada vez mais, também sujeitos da visão. Este é o ponto de encontro das noções, a princípio antagônicas, de vigilância e espetáculo. No primeiro caso, como já vimos, o problema consiste em adentrar o campo de visão de um poder que tudo vê, ser objeto do olhar. A visão é um dos instrumentos de que este poder se vale para atuar sobre e produzir os sujeitos, condicionar suas ações, domesticá-los. Isto é: os investimentos do poder redundam em respostas ativas e operacionais inscritas nos corpos dos sujeitos. Na noção de espetáculo de Debord (1997), a resposta dos indivíduos é passiva: a ausência de ação e a atomização do indivíduo decorrem da posição não de objeto, mas de sujeito da visão. Hipnotizado pelo fluxo das imagens, um sujeito petrificado e impotente se isola.

Portanto, se a dissuasão falha, produz-se uma imagem de grande apelo ao público contemporâneo. A eficácia de um atentado como o perpetrado contra as torres gêmeas - na verdade, de tudo o que se enquadra na definição atual de terrorismo - está em outra premeditação, a dos autores dos atos, que calculam antecipadamente a circulação intensiva de imagens, relatos e narrativas do horror.

Para a grande maioria do público, as explosões do WTC aconteceram na tela dos televisores, e a imagem exaustivamente repetida das pessoas correndo aterrorizadas em direção às câmeras seguidas pela nuvem de poeira da torre derrubada foi enquadrada de forma a lembrar as tomadas espetaculares dos filmes de catástrofe, um efeito especial que superou todos os outros. [...] Os próprios "terroristas" não o fizeram primariamente visando provocar dano material real, mas pelo seu efeito espetacular. (ZIZEK, 2003: 25)

Uma série de fatores leva este acontecimento específico a ser qualificado costumeiramente como "espetacular": desde a grandiosidade dos alvos (física e simbólica), a quantidade de vítimas, a forma de interrupção brusca e chocante e, principalmente, a disponibilidade até então inédita de registros audiovisuais das ocorrências relacionadas - a natureza eminentemente imagética da narrativa sobre a tragédia.

Um episódio como o ataque às torres do WTC provoca uma interrupção brusca no cotidiano e magnetiza a atenção do público diante das telas. A deflagração súbita e inesperada e a estrutura de choque desses eventos expressam, de modo extremo e brutal, uma forma-acontecimento especialmente mobilizadora da atenção contemporânea. Na verdade, as catástrofes que invadem subitamente a realidade sempre impactaram o público e serviram de material farto aos 
${ }^{11}$ Há um trecho do vídeo disponível em: http://bit.ly/2MezDb8.

Acesso em: 13 nov. 2018.

\footnotetext{
${ }^{12}$ Há uma série de versões deste fragmento do vídeo de Hlava no YouTube. É difícil determinar se e quando os espectadores estão informados sobre os detalhes da filmagem. Na versão analisada aqui, um pequeno fragmento de 18 segundos, a informação de que o cinegrafista não percebeu as explosões consta nos comentários da página do YouTube. Alguns dos vídeos que encontramos são reportagens de emissoras norte-americanas, as quais, invariavelmente, revelam este aspecto inusitado. É o caso dessa reportagem da emissora de TV ABC, a primeira a divulgar o vídeo de Hlava, dois anos
} depois dos atentados: http://bit. Iy/2XbTpEY. Acesso em: 13 nov. 2018. meios de comunicação. Singer (2010: 96) mostra, por exemplo, o vínculo entre o crescimento do jornalismo sensacionalista no final do século XIX e a experiência subjetiva da vida urbana moderna, crescentemente marcada pelo choque perceptivo e físico, pela urgência e o "bombardeiro de estímulos" - revelando a ligação entre as estéticas do espanto e da ruptura e a modernidade, período "marcadamente mais rápido, caótico, fragmentado e desorientador do que as fases anteriores da cultura humana".

\section{Flagrante duplamente acidenta}

Outro flagrante audiovisual do impacto do primeiro avião ${ }^{11}$, esse de autoria de um cinegrafista amador, é novamente expressão tanto de um regime de atenção vigilante quanto do que se poderia chamar de uma visão sem olhar. É mais um a capturar inadvertidamente um acontecimento que invade o campo de visão. O cinegrafista encontra-se dentro do carro, no banco do carona, engarrafado na entrada de um túnel. Ele movimenta a câmera para o lado direito e as duas torres do World Trade Center surgem no quadro, distantes, diminutas. Ao percebêlas, aciona o zoom para enquadrá-las. Uma das torres quase tapa a outra. No momento em que o zoom é acionado e nos aproximamos dos edifícios, vê-se uma pequena bola de fumaça na torre parcialmente ocultada. A fumaça rapidamente se expande, mas, por alguns instantes, o cinegrafista enquadra o topo da torre e a explosão desaparece do plano - trata-se de uma filmagem particularmente tremida. Em seguida, o zoom recua, nos afasta das torres e a câmera mira mais uma vez o engarrafamento, o túnel. O carro retoma seu trajeto. Tudo isso dura 18 segundos.

Comparado à vasta coleção de registros relacionados ao 11 de setembro, nos quais é possível distinguir claramente as ocorrências violentas e espetaculares e, em alguns casos, perceber as reações corporais de cinegrafistas engajados no acontecimento -, esse vídeo pode ser considerado excessivamente caótico e vacilante, no qual a inscrição do acontecimento ocupa uma posiçãolateral e discreta. A singularidade da imagem reside na sua raridade: uma das três documentações visuais do primeiro impacto. Chama a atenção a falta de uma reação mais contundente do cinegrafista e demais ocupantes do automóvel diante do evento perturbador e surpreendente recém testemunhado. 0 operador avança o zoom em direção às torres no momento exato em que irrompe a fumaça e a vacilação no enquadramento do evento parece um reflexo ao susto provocado. Porém, não há qualquer fala ou reação no plano sonoro - gritos de surpresa são uma constante nos flagrantes do atentado ao WTC. A câmera simplesmente volta à posição original com a atenção fixada no trânsito, como que retomando o foco no trajeto após um lapso irrelevante.

A estranha reação - ou a falta dela - pode ser compreendida com informações sobre o vídeo externas à imagem em $\mathrm{si}$, mas, via de regra, presentes nos contextos de exibição $0^{12}$. De acordo com Glanz (2003), o cinegrafista, um imigrante tcheco chamado Pavel Hlava não percebeu que havia documentado, naquele instante, uma enorme explosão em uma das torres do WTC. Ele só reparou no registro duas semanas depois do atentado. No momento da captação, Hlava olhava não pelo visor, mas para o display de sua câmera de vídeo digital, que reproduzia a imagem em baixa resolução. Trabalhador do setor da construção civil, ele filmava um vídeo sobre Nova York para enviar aos familiares na República Tcheca. Um vídeo que remete a uma das tradições do cinema amador: os filmes de viagem, em que um cinegrafista capta vistas de algum lugar distante para um público predominantemente familiar. Mas também alude à relação dos sujeitos com o espaço urbano, apropriada no modo de imagens que gradualmente decalcam toda sua superfície.

Hlava ocupava o assento de passageiro da caminhonete do dono da construtora onde trabalhava. Quando avistou as torres do World Trade Center, ampliou o 
${ }^{13}$ Informações retiradas da reportagem de Glanz (2003), publicada no jornal New York Times. Disponível em: https://nyti.ms/2wlQ2j6.

Acesso em: 13 nov. 2018.

${ }^{14}$ Há um trecho do registro do choque do segundo avião neste endereço: http://bit.ly/2MevBPN. Acesso em: 13 nov. 2018. zoom para enquadrá-las. Depois da captação acidental, sem perceber o conteúdo da filmagem, manteve a câmera ligada enquanto o veículo prosseguia ${ }^{13}$. Do outro lado do túnel, já muito mais próximo do WTC, deparou-se com a torre norte em chamas. Hlava aponta a câmera novamente para o prédio, cujo topo aparece tomado de uma fumaça escura, e flagra o instante em que o segundo avião se choca contra a torre sul. Portanto, o mesmo vídeo, produto de uma câmera a filmar/vigiar a cidade de Nova York na manhã de 11 de setembro de 2001, registrou os dois impactos. Vista de baixo, com a torre ainda intacta centralizada, a filmagem dá a ver o impacto com grande clareza - ouvimos o barulho da aeronave se aproximando, adentrando o prédio e provocando uma enorme explosão. É um dos vídeos mais próximos e impressionantes do segundo impacto ${ }^{14}$. Não temos acesso ao filme completo, apenas a versões curtas, separadas entre si - uma amostra clara, aliás, da fragmentação que é o traço essencial nos espaços de exibição da web, sobretudo o YouTube.

O vídeo do primeiro choque revela uma estranheza um tanto incompreensível. Se observamos apenas a imagem em busca de seus efeitos de sentido - esquecendo por um momento a informação de que o cinegrafista não viu o que filmou -, surpreende o modo como a câmera simplesmente abandona as torres gêmeas logo depois de flagrar uma enorme explosão. Em contrapartida, se examinamos o vídeo cientes do desconhecimento por parte do operador, espanta a coincidência temporal do zoom, aproximando-se das torres no exato momento do choque. Parece haver uma intencionalidade a dirigir o enquadramento neste momento decisivo. Assim como o flagrante da webcam do artista alemão Wolfgang Staehle, essa outra captação do instante inaugural do ataque de 11 de setembro concede o protagonismo à máquina. Um automatismo uma escala acima daquele associado às tecnologias de captação de imagem desde o surgimento da fotografia, nos quais a participação humana resume-se, supostamente, a apertar um botão. Em ambos os casos, na webcam e neste vídeo amador, embora existam as diferenças formais óbvias, há registro - literalmente - sem olhar humano. É como se a imagem se fizesse sozinha.

No primeiro caso, a obra de Staehle, o automatismo é óbvio: há uma câmera fixa em funcionamento perpétuo. Ninguém a opera. No segundo, cujas particularidades formais diferem sensivelmente, constituindo uma câmera-subjetiva, o olhar propriamente dito é o da máquina - o cinegrafista apenas a opera, desatento. Resume-se a acionar o zoom mecânica e distraidamente quando nos arredores das torres gêmeas, essa atração turística nova-iorquina. E isso no interior de outra máquina, o automóvel. Ora, daquela posição o olho humano de fato não veria a explosão: é graças ao zoom, ao jogo de lente que só a máquina alcança. Em O homem com a câmera (1929) de Dziga Vertov, Comolli (2008) vê a conjunção do cine-olho, onipotente, com a impotência do olho humano. "Um olho infalível se junta ao olho cegado que é o nosso" (COMOLLI: 239). Nesta filmagem - que também se move e explora a cidade, mas já numa lógica consumista do turismo -, a substituição está completa.

Com sua mecanização, hoje sua informatização, a soltura [da câmera] se põe evidentemente a serviço de outra escritura, provavelmente de outro projeto; a câmera se torna um olho frio, perfeitamente esvaziado da referência ao humano que o cinema ainda carregava em seu apogeu. (AUMONT, 2004: 70)

É importante frisar, no entanto, os efeitos opostos das duas documentações visuais do choque inaugural do atentado. Fruto de duas câmeras superpostas, a imagem panorâmica de Staehle - um díptico - não reproduz o olhar humano, inapto a tal amplitude de visão. Como já comentado, trata-se de uma imagem gélida. Já o vídeo de Hlava traz os ruídos típicos das filmagens amadoras, que possui entre seus efeitos a remissão permanente à presença do operador - de um 
corpo humano cujos movimentos refletem em movimentos na câmera. $O$ efeito é de engajamento na cena tanto do cinegrafista quanto do espectador, produzindo um realismo calcado na subjetividade. Essa marcação da presença do operador que, ao acionar o zoom, parece interessado em enquadrar a explosão - engana sobre o automatismo da operação, produzindo o já mencionado estranhamento quando o enquadramento simplesmente retoma o trajeto e desconhece a explosão extraordinária que acabou de ver.

Para as testemunhas presentes na cena onde a catástrofe se desenrola, a pulsão escópica cada vez mais se transfere do olho para a câmera: o ímpeto de ver vira necessidade de filmar e fotografar, movimento anunciador de uma hibridização entre consumo e produção de imagens, entre ver e registrar, entre as posições de espectador e produtor. Há o interesse de documentar fatos de tal significância, talvez abastecer os meios de comunicação. Porém, a pulsão de olhar através da e junto com a câmera parece atender também a uma demanda restrita ao ato da filmagem, que se basta àquele momento: a de simplesmente substituir a visão do olho pelo registro visual com um equipamento, independentemente do destino que vá ter a imagem gerada.

Outras imagens amadoras produzidas no entorno das torres no 11 de setembro

${ }^{15} \mathrm{O}$ vídeo encontra-se disponível neste link: http://bit.ly/2K94052. Acesso em: 25 maio 2017. exibem essa característica: o ímpeto de continuar filmando ininterruptamente, ainda que o cinegrafista pareça estar em risco. Em um vídeo ${ }^{15}$ de 25 minutos tomado de um quarto de hotel bastante próximo das torres, na maior parte do tempo, o cinegrafista enquadra os dois prédios em chamas. O filme longo, em se tratando de imagens precárias exibidas no YouTube, transmite de modo eficaz a experiência de presenciar esse acontecimento violento tão de perto. A estética amadora potencializa esse efeito de estar lá: neste exemplo, sobretudo o uso inábil do zoom, a textura que remete ao vídeo e a ausência de narração. 0 cinegrafista não aparece, mas logo fica claro tratar-se de um homem situado no quarto de hotel com a esposa. Protagonizado por um casal, remete à intimidade dos filmes de família.

Eles conversam pouco entre si, a televisão está ligada em alguma emissora que cobre a tragédia, ela fala ao telefone com outra pessoa, descreve o que vê através da janela: a cena que o marido filma. De modo geral, surpreende as reações um tanto comedidas, pouco dramáticas e efusivas, nos momentos críticos: quando percebem que há corpos caindo e quando ele direciona a câmera para alguns desses corpos e comenta que parecem desintegrados (ao espectador essa imagem não é clara); quando há o choque do segundo avião, que o vídeo não enquadra, mas registra na forma de som; e nos momentos em que comentam o perigo que podem estar correndo. A falta de manifestações mais intensas e os reincidentes lapsos de silêncio contrastam com a violência eloquente que domina o quadro, os dois prédios queimando, a fumaça cada vez mais escura e volumosa, tudo muito próximo da janela do hotel. Dada a distância tão pequena, é natural questionar-se sobre o risco ao qual o casal está submetido. Ainda assim, a filmagem prossegue.

Portanto, este documento potente e realista sobre a experiência de testemunhar, de um ponto de vista próximo, o ataque às torres gêmeas - sobre a confusão inicial com o primeiro choque, o segundo impacto e a certeza do terrorismo, a cena de horror dos corpos em queda, o desabamento das torres -, mostra que essa experiência específica envolveu, em algum nível, a mediação de um equipamento de filmagem. O efeito realista alude a uma reprodução direta e imediata; sabemos que é um documento tomado diante do próprio acontecimento e as reações registradas em situação limite deste nível só podem ser espontâneas. Ainda que comedidas, as reações são autênticas - quando do estrondo do segundo avião, o cinegrafista joga a câmera na cama, filma o lençol por alguns segundos, enquanto especula com a esposa sobre o que está ocorrendo. Essa autenticidade nas reações e atitudes, que inclusive refletem no movimento de câmera, convive com 
${ }^{16}$ Nascidos na França mas naturalizados norte-americanos, os irmãos Naudet produziam um documentário sobre um grupo de bombeiros nova-iorquinos quando foram surpreendidos pelo ataque. Os cineastas acompanharam as operações de salvamento dentro das torres gêmeas, filmagens que originaram o filme $9 / 11$, lançado um ano depois.

\section{${ }^{17} \mathrm{O}$ vídeo pode ser visto neste} link: http://bit.ly/2K8FnjN. Acesso em: 23 maio 2017. a pulsão de filmar, de verter o acontecimento em filme. Há aqui indícios de um alto grau de naturalização do gesto de registrar o mundo em imagem.

Diante de um evento imponente como este, o reflexo de acionar a câmera parece mais óbvio, dadas a importância e a repercussão, mas também estranho e incômodo: há perigo envolvido e talvez haja outras preocupações prioritárias. Seja como for, este gesto de registro como reação à eclosão de algum fato parece cada vez mais automatizado.

\section{Imagens violentas}

O terceiro registro da colisão do primeiro avião contra o WTC é de autoria dos documentaristas Jules e Gédéon Naudet ${ }^{16}$, que filmavam nas ruas de Manhattan quando a primeira aeronave subitamente invadiu a cena. Temos acesso apenas a uma versão bastante reduzida disponível no YouTube ${ }^{17}$. Cerca de três segundos depois de iniciada a exibição do vídeo, um corpo estranho, um ruído sonoro e uma enorme sombra fora de campo, no alto, interrompem a cena ordinária que enquadrava um bombeiro parado numa esquina qualquer de Nova York. 0 cinegrafista mira o alvo móvel e aponta a câmera para o horizonte, onde estão as duas torres do WTC. Após quatro segundos, a aeronave choca-se contra a torre. 0 operador aciona o zoom e aproxima do ponto atingido pelo ataque. Registra fogo e fumaça brotando da torre. Ao fundo, ouvem-se gritos de surpresa e alarme.

Este, mais do que os demais, é um registro que expressa a interrupção do cotidiano (no vídeo de Hlava, a explosão encontra-se tão lateral e discreta que parece irrelevante, um fato ordinário - e não a ruptura da normalidade provocada pela irrupção de um acontecimento espetacular). Na medida em que atravessa explicitamente uma filmagem em andamento e sequestra a atenção da câmera e do operador, transmite a ideia de ruptura abrupta e imprevista. $O$ instante do impacto do avião com a torre é também o ponto de inflexão do acontecimento. Esse momento desestabilizador e instaurador de descontinuidade está expresso no próprio vídeo, na sua estrutura de choque.

Filmado da altura do chão com um equipamento portátil, reproduz a experiência de um sujeito que transitava pelas ruas de Manhattan e teve sua atenção subitamente capturada pela emergência do avião. É este o efeito que o vídeo produz: a invasão da imagem por um objeto que mobiliza o olhar da câmera e do sujeito que a opera. Assim que surge o barulho intenso do avião, o bombeiro enquadrado na cena desvia o rosto e a atenção para o alto. Em seguida, a própria câmera repete o mesmo movimento.

Em texto que analisa imagens do atentado ao WTC, Jost (2004) contrasta os "nobody shots" ("tomadas de ninguém") das grandes emissoras de televisão planos gerais das duas torres posicionados a longas distâncias - com os registros em câmera portátil operados por amadores, jornalistas, documentaristas: estas "na altura do homem" e com "ancoragem num olhar humano" (p. 75). Cunha então a expressão "imagens violentas" para definir essas imagens instáveis, realizadas com câmera na mão, por cinegrafistas que também se preocupavam em escapar do perigo. Em oposição, estão as "imagens de violência" da TV, planos impressionantes que mostram ocorrências brutais, mas incapazes de transmitir a sensação corporal além da visão. As "imagens violentas" causam choques perceptivos ao propiciar uma "identificação com o corpo do cineasta, a construção de uma humanidade por trás da câmera" (p. 81).

Este é um exemplo típico de uma "imagem violenta" ancorada na experiência subjetiva do cinegrafista e que remete não apenas a um olhar humano, mas transmite o choque perceptivo decorrente da explosão próxima. Simultâneo ao efeito sensório, há a visão privilegiada do acontecimento, que torna este o documento a oferecer o testemunho visual mais claro do impacto do 
primeiro avião. No vídeo dá para ver o choque e a explosão no centro de seu enquadramento. Isto é: trata-se de uma imagem cuja força de verdade sustentase tanto na assunção deliberada do caráter testemunhal, subjetivo, recortado ponto de vista de um sujeito específico - quanto da evidência imposta pelo próprio conteúdo pró-fílmico, fato espetacular e grandioso que transcorre sem qualquer influência do cinegrafista. É uma circunstância não-premeditada que, uma vez desencadeada, passa explicitamente a dirigir os movimentos da câmera móvel: o enquadramento responde aos sobressaltos que são da ordem do referente, uma postura reativa do operador.

Portanto, há, nesse vídeo, uma primazia do objeto filmado no jogo entre sujeito, câmera e mundo. São os eventos decorrentes de contingências externas ao sujeito que governam a operação de filmagem (enquadramentos, movimentos de câmera, zoom, duração do plano). Nesse vídeo, o sujeito situado diante do acontecimento filmado sobretudo responde a este chamado do mundo. E o evento que interpela e governa o cameraman acidental são também o que atrai o olho do espectador.

Diante da visão extraordinária das duas torres do WTC em chamas, o cinegrafista opera sua câmera sem qualquer possibilidade de interferir naquilo que registra. As imagens de catástrofes demonstram, de modo extremo, o efeito de real calcado no testemunho de eventos inesperados e abruptos, cuja circunstância de produção não-premeditada revela-se irrepetível.

A ameaça do inesperado - afinal, como dizia Bazin (2014), os fatos da história não são como um balé programado de antemão - sempre foi um apelo das gravações ao vivo. Nelas, é relevante e atraente o risco imponderável associado a uma "arte do improviso" que "incorpora o aleatório e o imprevisível na própria construção da obra" (MACHADO, 2000: 135). Há uma indefinição e indecidibilidade fundamentais: a possibilidade de intervenção do imponderável paira o tempo todo, tornando a imagem "indomesticável". Embora inúmeras vezes acidentes, erros e imprevistos ocorram, o fundamental na experiência fenomenológica da transmissão ao vivo consiste no risco. Isto é: mais essencial na ontologia do ao vivo é a ameaça mais ou menos velada do equívoco - essa abertura ao acaso em constante oposição aos esforços de controle e programação por parte da produção - do que o acidente de fato.

Ora, nos registros que captam uma irrupção inesperada, a intervenção já está dada. Se, como quer Eco (1968), a transmissão ao vivo é uma obra aberta, os vídeos aqui analisados são obras já fechadas. $O$ fato de o lance de dados do destino ter atuado é que os faz destacar-se da mesmice dos registros amadores cotidianos e circular massivamente. A imagem chega ao espectador já indexada como registro audiovisual de um flagrante. Ainda assim, o imponderável e a indeterminação das condições originais de produção do vídeo encontram-se inscritos no material imagético.

Embora a transmissão direta propriamente dita seja uma experiência fenomenológica específica, imprevisível e irrepetível, o seu registro em fita magnética ainda guarda parte das marcas de incompletude e de intervenção do acaso, impossíveis de encontrar em trabalhos realizados em outras situações produtivas. (MACHADO, 2000: 126)

\section{Conclusão: vigilância e espetáculo}

Para Crary (2012: 11), as transformações recentes no regime visual encaminham para um deslocamento da "visão para um plano dissociado do observador humano". O autor tem em mente, aqui, principalmente os modos de representação criados no âmbito dos programas de computador, inclusive de feição realista. 
${ }^{18}$ Um caso notório é o da onda de filmes de horror found footage, cuja trama gira em torno de uma gravação geralmente produzida por amadores. Esse cinema vale-se dos sentidos de intimidade e de espontaneidade das filmagens caseiras para produzir novos efeitos de real.

${ }^{19}$ Como comentamos, o próprio artista optou por uma postura de discrição, evitando debates sobre a obra e recusando-se a disponibilizar as imagens às emissoras de televisão na época do atentado (FRIEND, 2011).
Em meio à escalada de imagens simuladas, multiplicam-se também as filmagens de câmera de segurança igualmente dotadas de um olhar maquínico, com ponto de vista fixado em posições inusitadas e uma operação a registrar o vazio ininterruptamente, anos a fio. Se há a eventual captação de um crime, trata-se de uma falha de um sistema cuja missão é dissuadir ações pela via do controle.

Em paralelo às imagens gélidas das máquinas - mas também no interior de um regime de vigilância -, temos a infinidade de registros visuais tomados pelos sujeitos que vagam pelas ruas dotados de câmeras incorporadas aos mais variados equipamentos. Essas imagens tomadas espontaneamente, seja de situações cotidianas, seja de ocorrências extraordinárias a interromperem a normalidade, estão dotadas de renovados efeitos realistas. Transmitem uma carga de autenticidade ao espectador contemporâneo, tendo sua estética inclusive emulada no cinema em busca de naturalismo ${ }^{18}$, imediaticidade, entre outros efeitos. $\mathrm{O}$ apelo dessas imagens que acabam apropriadas pelo discurso midiático tradicional e/ou circulam massivamente nas redes sociais vira, entre outras coisas, incitamento à produção de mais imagens de si e do mundo. Registros visuais chocantes sobretudo trágicos, violentos - mais do que nunca magnetizam espectadores em frente às telas, um público tornado partícipe ao compartilhar e comentar esses objetos audiovisuais. Vigilância e espetacularização caminham juntos.

Em 11 de setembro de 2001, a configuração da cultura digital era diferente: não havia redes sociais e os celulares não agregavam câmera. Ainda assim, pode-se perceber nessa catástrofe uma série de vetores deste regime marcado não apenas pela profusão de imagens, mas principalmente pela extensão da abrangência do universo visível - e, se tem algo que os terroristas que arquitetaram o ato almejavam, era visibilidade. O ímpeto de duplicação do mundo em imagem/ simulacro (BAUDRILLARD, 1991) alcança outra escala quantitativa. A constatação quanto à presença permanente de câmeras filmando as diversas partes de uma cidade como Nova York está na existência de três registros audiovisuais do choque inaugural e imprevisto do atentado contra o WTC. A filmagem fixa e vigilante da obra de arte de Wolfgang Staehle que, contraditoriamente, buscava enfatizar o vazio de acontecimentos das imagens de vigilância e, dada a frieza com que documenta o acontecimento, retira espetacularidade, de certa forma esvaziando-o com seu olhar sem desejo. Não à toa, tal imagem esteve ausente das narrativas visuais sobre este acontecimento hipernoticiado e é pouco conhecida mesmo entre os estudiosos da arte e das imagens ${ }^{19}$.

No vídeo amador do imigrante Pavel Hlava, no qual o cinegrafista sequer percebe a explosão captada no instante em que o zoom aproxima a filmagem das torres, a imagem desconhece e, de certo modo, ignora seu próprio conteúdo. Embora os efeitos sejam sensivelmente diferentes da obra de Staehle, dadas as marcas estéticas do vídeo amador, temos novamente uma captação acidental cujo dispositivo não parece afetado pelo fato extraordinário documentado, uma indiferença que retira humanidade da imagem. No longo vídeo do casal que assiste a destruição das torres do quarto de hotel, a mediação da câmera produz sentido diverso: ainda que haja a interposição da máquina entre o olho e o fato, o dispositivo expressa tanto a incredulidade quanto a impotência dos sujeitos diante da catástrofe tão próxima. O terceiro registro do primeiro choque, que dá a ver o impacto no centro da imagem, sem barreiras, também remete a um olhar antropocêntrico, apesar do recurso ao zoom. Na verdade, mais do que ao olhar, alude à presença de corpos afetados pela intrusão do avião na cena e pelo choque seguido de explosão, seja o corpo do cinegrafista seja os sujeitos enquadrados que reagem à irrupção imprevista. Resíduo de humanidade em registros crescentemente automatizados? 


\section{Referências}

AUMONT, J. O olho interminável. São Paulo: Cosac \& Naify, 2004.

BAUDRILLARD, J. Simulacros e simulação. Lisboa: Relógio D’Água, 1991.

BAZIN, A. Sobre Why we fight. In: BAZIN, A. O que é o cinema? São Paulo: Cosac Naify, 2014. p. 41-46.

BRUNO, F. Máquinas de ver, modos de ser: visibilidade e subjetividade nas novas tecnologias de informação e de comunicação. Revista Famecos, Porto Alegre, v. 11, n. 24, p. 110-124, 2004.

BRUNO, F. Estética do flagrante: controle e prazer nos dispositivos de vigilância contemporâneos. Revista Cinética, [S.I.], 2007.Disponível em: http://bit.ly/2JIrEB2. Acesso em: 13 maio 2019.

COMOLLI, J. Ver e poder: a inocência perdida - cinema, televisão, ficção, documentário. Belo Horizonte: Editora UFMG, 2008.

CRARY, J. Técnicas do observador: visão e modernidade no século XIX. Rio de Janeiro: Contraponto, 2012.

DEBORD, G. A sociedade do espetáculo. Rio de Janeiro: Contraponto, 1997.

DELEUZE, G. Post-scriptum sobre as sociedades de controle. In: DELEUZE, G. Conversações. São Paulo: Editora 34, 1992. p. 219-226.

DUBOIS, P. Cinema, vídeo, Godard. São Paulo: Cosac Naify, 2004.

ECO, U. A obra aberta. São Paulo: Perspectiva, 1968.

FOUCAULT, M. Vigiar e punir. Petrópolis: Vozes, 1987.

FRIEND, D. Watching the world change: the stories behind the images of 9/11. New York: Picador, 2006.

GLANZ, J. A rare view of 9/11, overlooked. The New York Times, New York, 7 set. 2003. Disponível em: https://nyti.ms/2wlQ2j6. Acesso em: 25 maio 2017.

JOST, F. O saber do espectador e o saber do telespectador. Significação, São Paulo, v. 31, n. 21, p. 63-84, 2004.

LYON, D. 11 de setembro, sinóptico e escopofilia: observando e sendo observado. In: BRUNO, F.; KANASHIRO, M.; FIRMINO, R. (org.). Vigilância e visibilidade: espaço, tecnologia e identificação. Porto Alegre: Sulina, 2010. p. 115-140.

MACHADO, A. A televisão levada a sério. São Paulo: Senac, 2000.

MENICK, J. Real-time futures: five notes on the work of Wolfgang Staehle. Parachute, Montreal, n. 113, 2004. Não paginado.

RODNEY, L. Real time, catastrophe, spectacle: reality as fantasy in live media. In: KING, G (org.). The spectacle of the real. Bristol: Intellect, 2005. p. 37-46.

SINGER, B. Modernidade, hiperestímulo e o início do sensacionalismo popular. In: CHARNEY, L.; SCHWARTZ, V (org.). O cinema e a invenção da vida moderna. São Paulo: Cosac Naify, 2010. p. 95-126.

ZIZEK, S. Bem-vindo ao deserto do real! São Paulo: Boitempo, 2003. 


\section{Filmografia}

1st PLANE crashing into World Trade Center. [filme amador] Direção: Jules Naudet. Prod. privada. Estados Unidos, 2001, $14 \mathrm{seg}$.

2001. [videoinstalação]. Direção: Wolfgang Staehle. Estados Unidos, Galeria Postmasters, 2001.

9/11. Direção: Gédéon Naudet, James Hanlon. Prod. CBS. Estados Unidos, 2002, $112 \mathrm{~min}$.

EMPIRE 24/7. [videoinstalação]. Direção: Wolfgang Staehle. Alemanha, ZKM, 1996.

EMPIRE. Direção: Andy Warhol. Prod. Andy Warhol. Estados Unidos, 1968, 485min.

RAW 9/11: Footage from a Hotel Window. [filme amador]. Direção: desconhecido. Prod. privada. Estados Unidos, 2001, 25 min.

WHY we fight. Direção: Frank Capra. Prod. Governo dos Estados Unidos. Estados Unidos, 1942-1945, 401min.

WTC 1st attack. [filme amador]. Direção: Pavel Hlava. Prod. privada. Estados Unidos, 2001, 17 seg.

WTC 2st attack. [filme amador]. Direção: Pavel Hlava. Prod. privada. Estados Unidos, 2001, 2 min 26 seg. 